\title{
BMJ Open Prevalence of asymptomatic carotid artery stenosis in Chinese patients with lower extremity peripheral arterial disease: a cross-sectional study on 653 patients
}

\author{
Zhui Li, ${ }^{1}$ Hong Yang, ${ }^{2}$ Wenfang Zhang, ${ }^{2}$ Jing Wang, ${ }^{2}$ Yu Zhao, ${ }^{1}$ Jun Cheng (i) ${ }^{1}$
}

To cite: Li Z, Yang $\mathrm{H}$, Zhang W, et al. Prevalence of asymptomatic carotid artery stenosis in Chinese patients with lower extremity peripheral arterial disease: a cross-sectional study on 653 patients. BMJ Open 2021;11:e042926. doi:10.1136/ bmjopen-2020-042926

- Prepublication history for this paper is available online. To view these files, please visit the journal online ().

Received 19 July 2020 Revised 07 April 2021 Accepted 08 April 2021

A) Check for updates

(C) Author(s) (or their employer(s)) 2021. Re-use permitted under CC BY-NC. No commercial re-use. See rights and permissions. Published by BMJ.

${ }^{1}$ Department of Vascular Surgery, the First Affiliated Hospital of Chongqing Medical University, Chongqing, China ${ }^{2}$ Departments of Ultrasound, the First Affiliated Hospital of Chongqing Medical University, Chongqing, China

Correspondence to

Dr Jun Cheng;

chengjun2020@yeah.net

\section{ABSTRACT}

Objective This study aimed to investigate the prevalence and identify predictive factors of asymptomatic carotid artery stenosis (ACAS) in Southern Chinese patients with peripheral arterial disease (PAD).

Design A cross-sectional study.

Setting and participants $A$ total of 653 patients with PAD admitted to the First Affiliated Hospital of Chongqing Medical University from July 2014 to July 2019.

Main outcome measures The degree of carotid stenosis was assessed by Duplex ultrasound and classified as normal (no stenosis), mild ( $<50 \%$ stenosis), moderate (50\%-69\% stenosis), severe ( $\geq 70 \%$ stenosis or near occlusion) and total occlusion. Patients with stenosis $\geq 50 \%$ were classified as having significant ACAS. Multivariable logistic regression analysis was used to calculate the risk associated with concomitant factors of ACAS.

Results The mean age was $71.5 \pm 5.5$ years, and $55.9 \%$ of the patients were men. Significant ACAS stenosis accounted for 128 (19.6\%) cases, including 68 (10.4\%) cases of moderate stenosis (50\%-69\%), 46 (7.0\%) cases of severe stenosis (70\%-99\%) and $14(2.1 \%)$ cases of total occlusion. Multivariable analysis revealed that age $\geq 70$ years (OR 2.0, 95\% $\mathrm{Cl} 1.25$ to 3.18 ), an ankle brachial index (ABI) $\leq 0.5$ (OR 3.39, 95\% Cl 1.34 to 8.55$)$, an $\mathrm{ABI}$ $\leq 0.4$ (OR 3.86, 95\% Cl 1.47 to 10.06) and Fontaine stage IV (OR 4.53, $95 \% \mathrm{Cl} 1.47$ to 13.88 ) are predictive factors of significant ACAS.

Conclusion The prevalence of significant ACAS (stenosis $\geq 50 \%$ ) in patients with PAD was approximately $19.6 \%$. Significant ACAS was more common in patients with PAD older than 70 years, particularly in patients with an $\mathrm{ABI}$ $<0.5$ and those classified as Fontaine stage IV. Selective carotid screening may be more worthwhile in these highrisk patients with PAD.

\section{INTRODUCTION}

Stroke is the second leading cause of death and a major cause of disability worldwide. ${ }^{2}$ The mortality rates for stroke of all types are approximately $15 \%$ at 1 month, $25 \%$ at 1 year and $50 \%$ at 5 years. ${ }^{3}$ Studies have shown that approximately $10 \%-48 \%$
Strengths and limitations of this study

- This study is the first to investigate the prevalence and risk factors of significant asymptomatic carotid stenosis in a large sample of Southern Chinese patients with lower extremity peripheral arterial disease.

- The cross-sectional study design allowed for multiple variables to be studied, and very few patients with missing data were excluded from the present study.

- The generalisability of the findings is limited because the study is a single-centre retrospective analysis and the participants consisted of only Southern Chinese patients.

- Prevalence and risk factors of asymptomatic carotid stenosis in patients with an ankle brachial index greater than 1.4 were not analysed.

of ischaemic strokes are caused by carotid artery stenosis (CAS). ${ }^{4}{ }^{5}$ Approximately $10 \%-15 \%$ of new strokes occurring each year will result from thromboembolism due to previously untreated asymptomatic CAS (ACAS). ${ }^{6}$ According to a systematic review and meta-analysis, the 5-year mortality rate for patients with ACAS greater than $50 \%$ was approximately $24 \%$, and $63 \%$ of deaths were the result of heart disease. ${ }^{7}$ However, low prevalence of ACAS was found in a population of 23706 people recruited from four population-based cohort studies, with estimated rates of $2.0 \%$ for $>50 \%$ stenosis and $0.5 \%$ for $>70 \%$ stenosis. ${ }^{8}$ Therefore, the Management of Atherosclerotic Carotid and Vertebral Artery Disease guidelines recommend against routine carotid screening at the general population level and support selective screening for patients with multiple vascular risk factors. ${ }^{9}$ Risk factor modification and optimal medical therapy in patients with 
screening-detected ACAS may significantly reduce the morbidity and mortality of cardiocerebrovascular events. The guidelines recommend that the purpose of carotid screening in high-risk patients is to optimise the control of risk factors and the administration of medical therapy to reduce late cardiovascular morbidity and mortality rather than to identify candidates for invasive surgical procedures.

Lower extremity peripheral arterial disease (PAD) and CAS are both local manifestations of systemic arteriosclerosis and usually share the same risk factors and pathological changes. Cardiovascular and cerebrovascular accidents are the most common cause of death in patients with PAD. Early identification of ACAS individuals based on investigations of high-risk factors in PAD populations may be beneficial to optimise the control of risk factors through medical therapy or lifestyle changes, thus reducing the mortality of these patients. The aim of the current study was to investigate the prevalence of ACAS in patients with symptomatic lower extremity PAD by screening the carotid artery with Duplex ultrasound (DUS) and to further explore the risk factors for $\geq 50 \%$ ACAS.

\section{MATERIALS AND METHODS \\ Study population}

Carotid ultrasound was performed on patients with PAD hospitalised at our hospital from July 2014 to July 2019. The inclusion criteria for patients with PAD were as follows ${ }^{10}$ : (1) decreased skin temperature, intermittent claudication, resting pain, lower limb numbness and cold sensation, foot ischaemic ulcers and gangrene (one or more of the above symptoms or signs); (2) a weak or absent arterial pulse at the distal end of the ischaemic limb; (3) an ankle brachial index $(\mathrm{ABI}) \leq 0.9$; and (4) stenosis or occlusion lesions of corresponding arteries confirmed by CT angiography (CTA), magnetic resonance angiography (MRA) or digital subtraction angiography. The following exclusion criteria were applied: (1) a history of ischaemic stroke, coronary artery disease or other carotid artery disease (carotid aneurysm, history of carotid artery trauma, etc); (2) lower limb ischaemia caused by diseases other than arteriosclerosis, such as thromboangiitis obliterans, acute or chronic arterial embolism, or Takayasu arteritis; (3) an ABI >1.4; and (4) refusal to undergo carotid ultrasound examination.

\section{Diagnosis of the degree of CAS}

Carotid DUS was performed in all patients with PAD who signed the informed consent form, and all internal carotid artery (ICA) and common carotid artery (CCA) examinations were performed using greyscale, colour Doppler and spectral Doppler ultrasound (Doppler US). The peak systolic velocity and end-diastolic velocity of the ICA and CCA were recorded. The ultrasound examinations were performed by a single sonographer with 8 years of vascular DUS experience using a GE LOGIQ-P5 system (GE Healthcare, Piscataway, New Jersey, USA). The CAS results were interpreted by a vascular surgeon with 15 years of vascular experience. CAS was defined by the degree of ICA stenosis according to the criteria of Society of Radiologists in Ultrasound Consensus Conference (SRUCC), ${ }^{11}$ and the degree of stenosis determined by greyscale and Doppler US was stratified into the categories of normal (no stenosis), mild $(<50 \%$ stenosis), moderate $(50 \%-69 \%$ stenosis $)$, severe $(\geq 70 \%$ stenosis but less than near occlusion or near occlusion) and total occlusion (table 1). In this study, patients with stenosis $\geq 50 \%$ were classified as having significant ACAS, and patients with stenosis $<50 \%$ were classified as having non-significant ACAS. The threshold of $50 \%$ stenosis was selected as the threshold currently used by most major vascular centres for medical therapy. ${ }^{9}$ After diagnosis of ACAS, patients were asked to take $100 \mathrm{mg}$ aspirin daily, as well as lipid-lowering therapy of either $40-80 \mathrm{mg}$ atorvastatin or 20-40 $\mathrm{mg}$ rosuvastatin aimed at achieving a

Table 1 Diagnostic criteria for ultrasound examination of carotid artery stenosis

Primary parameters

\begin{tabular}{|c|c|c|c|c|}
\hline Degree of stenosis (\%) & ICA PSV (cm/s) & $\begin{array}{l}\text { Plaque estimate } \\
(\%)^{\star}\end{array}$ & $\mathrm{PSV}_{\mathrm{ICA}} / \mathrm{PSV}_{\mathrm{CCA}}$ & ICA EDV $(\mathrm{cm} / \mathrm{s})$ \\
\hline Normal & $<125$ & None & $<2.0$ & $<40$ \\
\hline Moderate (50-69) & $125-230$ & $\geq 50$ & $2.0-4.0$ & $40-100$ \\
\hline $\begin{array}{l}\text { Severe ( } \geq 70 \text { but less than near } \\
\text { occlusion) }\end{array}$ & $>230$ & $\geq 50$ & $>4.0$ & $>100$ \\
\hline Total occlusion & Undetectable & $\begin{array}{l}\text { Visible, no detectable } \\
\text { lumen }\end{array}$ & Not applicable & Not applicable \\
\hline
\end{tabular}

*Plaque estimate (diameter reduction) with greyscale and colour Doppler ultrasound (US).

CCA, common carotid artery; EDV, end-diastolic velocity; ICA, internal carotid artery; PSV, peak systolic velocity. 
low-density lipoprotein (LDL) level of $<1.8 \mathrm{mmol} / \mathrm{L}$ (70 $\mathrm{mg} / \mathrm{dL}$ ) or a $50 \%$ reduction in LDL.

\section{Data collection}

Patient data including sex, age, body mass index (BMI), personal history (smoking, alcohol consumption), medical history (hypertension, type 2 diabetes, hypercholesterolaemia), degree of CAS, PAD lesions, Fontaine stage and ABI were obtained from the patients' medical records. The Fontaine stage was classified as follows: stage I: no symptoms or decreased skin temperature only and loss of dorsalis pedis and posterior tibial artery pulses; stage II: intermittent claudication; stage III: resting pain; and stage IV: gangrene or ischaemic ulcer. According to the location of arterial stenosis in the lower limb observed on imaging examinations, PAD lesions were classified as above-knee lesions, below-knee lesions and mixed lesions. $\mathrm{ABI}$ values of $1.00-1.40$ were classified as normal, and abnormal ABI values were divided into the following categories: $0.81-0.90,0.71-0.8,0.61-0.70,0.51-0.60,0.41-$ 0.50 and $\leq 0.4$. The diagnostic criteria for overweight and obesity were as follows $^{12}: 18.5 \leq \mathrm{BMI}<24 \mathrm{~kg} / \mathrm{m}^{2}$ was considered normal, $24 \leq \mathrm{BMI}<28 \mathrm{~kg} / \mathrm{m}^{2}$ was considered overweight and $\mathrm{BMI} \geq 28 \mathrm{~kg} / \mathrm{m}^{2}$ was considered obese. Patients who smoked in this study included current and former smokers. Current smokers were defined as those who had smoked greater than 100 cigarettes in their lifetime and had also smoked in the 30 days before admission to the hospital. Former smokers were defined as those who had smoked greater than 100 cigarettes in their lifetime but had not smoked in the 30 days prior to admission. ${ }^{13}$ Patients with alcohol consumption were defined as those who scored at least 8 on the Alcohol Use Disorders Identification Test. ${ }^{14}$ The criteria for the diagnosis of diabetes mellitus, hypercholesterolaemia and hypertension were established according to the corresponding guidelines.

\section{Statistical methods}

Calculation of the sample size before data collection indicated that the final sample size should be greater than 376 patients with $\mathrm{PAD}$. The samples in the study were collected consecutively. Four patients were excluded from the statistical analyses due to missing data on $\mathrm{ABI}$ and CTA, and five patients with ABI greater than 1.4 were also excluded from the statistical analyses. Thus, the final sample size was 653 patients (figure 1). The degree of CAS, PAD classification, Fontaine stage and ABI data of all patients were measured bilaterally, and the data for the more severe side were included in the statistical analysis. Continuous variable data are expressed as the mean \pm SD $(\mathrm{X} \pm \mathrm{SD})$, and categorical variables are expressed as percentages. The prevalence of CAS is expressed as the percentage of patients with different degrees of stenosis among all patients with PAD. Binary logistic regression was used to identify risk factors associated with significant ACAS. Continuous variables such as ABI, BMI and age were converted into categorical variables and were included in the logistic regression model as independent variables together with PAD lesions, Fontaine stage, sex, personal history and concomitant diseases. The degree of CAS was converted into a binary dependent variable at the $50 \%$ threshold. After ensuring no collinearity among the independent variables, ORs with 95\% CIs were used to analyse the strength of the associations between independent variables and dependent variables. A two-sided $p$ value $<0.05$ was considered statistically significant. Analyses were performed using IBM SPSS Statistics for Mac V.25.0 (IBM).

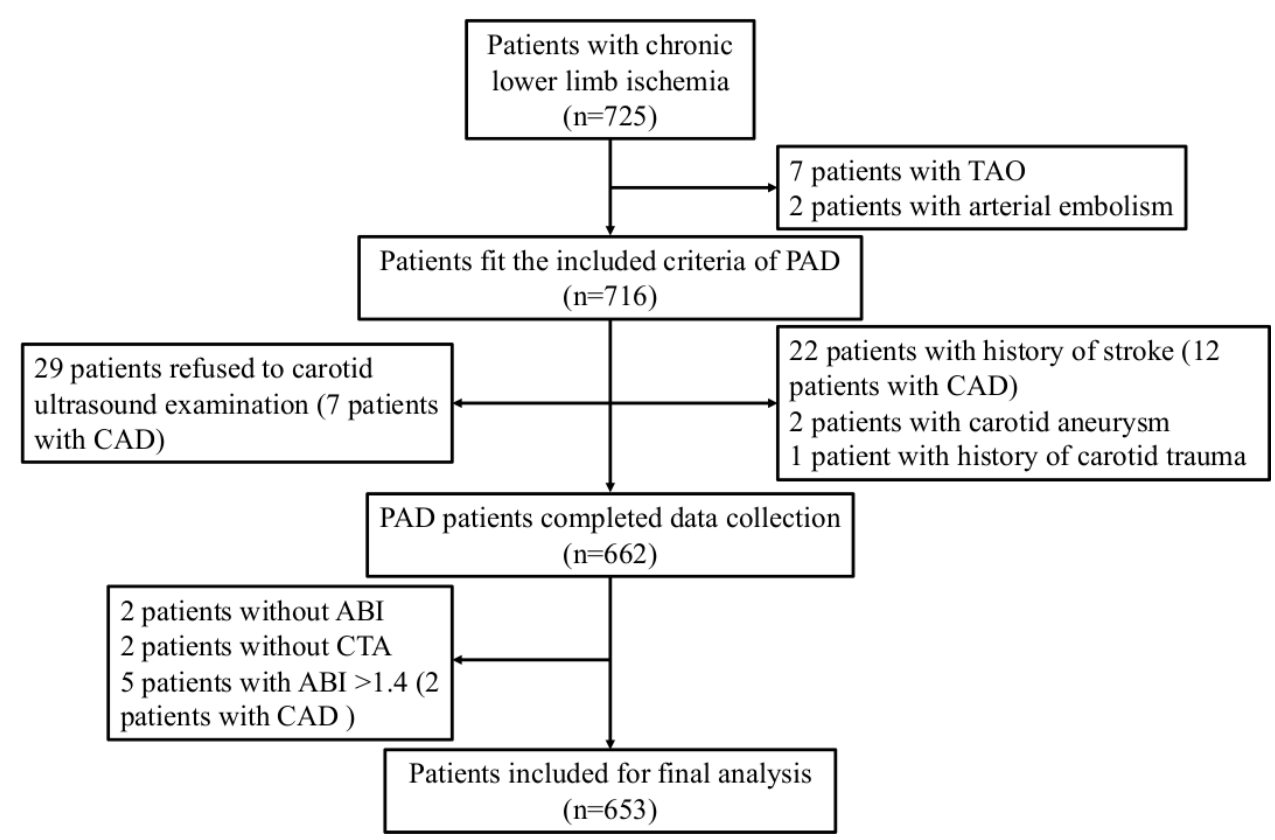

Figure 1 Flow chart of patients entering the data analysis set. ABI, ankle brachial index; CAD, coronary artery disease; CTA, CT angiography; PAD, peripheral arterial disease; TAO, thromboangiitis obliterans. 
Table 2 Clinical characteristics and demographics of the patients with PAD

\begin{tabular}{ll}
\hline Characteristic & $\begin{array}{l}\text { Patients with PAD } \\
\text { (n=653) }\end{array}$ \\
\hline Age (years) & $71.5 \pm 5.5$ \\
BMI (kg/m $\left.{ }^{2}\right)$ & $23.8 \pm 2.4$ \\
\hline Sex & \\
\hline Male & $365(55.9 \%)$ \\
\hline Female & $288(44.1 \%)$ \\
\hline Smoking & $251(38.4 \%)$ \\
\hline Alcohol consumption & $234(35.8 \%)$ \\
\hline Diabetes mellitus & $207(31.7 \%)$ \\
\hline Hypertension & $294(45.0 \%)$ \\
\hline Hypercholesterolaemia & $274(42.0 \%)$ \\
\hline ABI & \\
\hline $0.81-0.90$ & $108(16.5 \%)$ \\
\hline $0.71-0.80$ & $73(11.2 \%)$ \\
\hline $0.61-0.70$ & $146(22.4 \%)$ \\
\hline $0.51-0.60$ & $138(21.1 \%)$ \\
\hline $0.41-0.50$ & $112(17.2 \%)$ \\
\hline$\leq 0.4$ & $76(11.6 \%)$ \\
\hline Fontaine stage & \\
\hline I & $67(10.3 \%)$ \\
\hline II & $189(28.9 \%)$ \\
\hline III & $138(21.1 \%)$ \\
\hline IV & $259(39.7 \%)$ \\
\hline Besions & \\
\hline AK & $125(19.1 \%)$ \\
\hline Mixed & $269(41.2 \%)$ \\
\hline ABI, & $259(39.7 \%)$ \\
\hline
\end{tabular}

$\mathrm{ABI}$, ankle brachial index.; $\mathrm{AK}$, above the knee; $\mathrm{BK}$, below the knee; $B M I$, body mass index; PAD, peripheral arterial disease.

\section{Patient and public involvement}

Patients and the public were not involved with the study design, recruitment or execution of the study. No plans to disseminate the results of the research to the study participants are in place.

Table 3 Distribution of patients according to the degree of carotid artery stenosis

\begin{tabular}{|c|c|}
\hline Degree of carotid stenosis & Number of patients $(n=653)$ \\
\hline Normal & $238(36.6 \%)$ \\
\hline Mild stenosis (<50\%) & $287(44.0 \%)$ \\
\hline $\begin{array}{l}\text { Moderate stenosis }(50 \%- \\
69 \%)\end{array}$ & $68(10.4 \%)$ \\
\hline Severe stenosis (70\%-99\%) & $46(7.0 \%)$ \\
\hline Occlusion & $14(2.1 \%)$ \\
\hline
\end{tabular}

RESULTS

Clinical characteristics and demographics of the patients with PAD

A total of 653 patients with PAD with a mean age of $71.5 \pm 5.5$ years (ranging from 57 to 88 years), including 365 males and 288 females, met the enrolment criteria and were reviewed. Among these patients, $45 \%$ had hypertension, $32 \%$ had diabetes mellitus, $42 \%$ had hypercholesterolaemia, $38 \%$ had a history of smoking and $36 \%$ had a history of alcohol consumption. The mean ABI was 0.55 , and $49.9 \%$ of the patients had a value equal to or less than 0.60 . The clinical characteristics of the patients with PAD are detailed in table 2.

\section{Prevalence of CAS in patients with PAD}

A total of 653 eligible subjects (1306 carotid arteries) completed carotid artery ultrasound screening from July 2014 to July 2019; 238 patients $(36.6 \%)$ had normal carotid arteries, 287 patients $(44.0 \%)$ had less than $50 \%$ ICA stenosis, 68 patients $(10.4 \%)$ had 50\%-69\% ICA stenosis, 46 patients $(7.0 \%)$ had 70\%-99\% ICA stenosis and 14 patients $(2.1 \%)$ had total occlusion. ACAS of $50 \%-100 \%$ (moderate, severe and complete occlusion) was observed in $19.60 \%$ of all patients with PAD (table 3).

\section{Multivariable analysis of associated risk factors for significant} CAS in patients with PAD

In the multivariable logistic regression analysis, the risk factors for significant ACAS in patients with symptomatic PAD were age $>70$ years (OR 2.0, 95\% CI 1.25 to 3.18, $\mathrm{p}=0.004$ ), $\mathrm{ABI} \leq 0.5$ (OR $3.39,95 \%$ CI 1.34 to 8.55 , $\mathrm{p}=0.010), \mathrm{ABI} \leq 0.4$ (OR $3.86,95 \%$ CI 1.47 to 10.06 , $\mathrm{p}=0.006$ ) and Fontaine stage IV (OR 4.53, 95\% CI 1.47 to 13.88, $\mathrm{p}=0.008$ ). By contrast, sex, BMI, smoking, alcohol consumption, hypertension, hypercholesterolaemia and the location of lower limb arterial lesions had no effect on significant CAS (table 4).

\section{Prevalence of ICA stenosis in patients with PAD in other} countries

The prevalence rates of ICA stenosis in patients with PAD in previous studies conducted in other countries using the SRUCC diagnostic criteria are shown in table 5.

\section{DISCUSSION}

In the present study, DUS was used to screen the carotid arteries of 653 patients with PAD. We found that 415 patients with PAD $(415 / 653,63.6 \%)$ had CAS, and 128 patients $(128 / 653,19.6 \%)$ had $\geq 50 \%$ ACAS. Among these patients, $68(10.4 \%)$ had $50 \%-69 \%$ stenosis, 46 (7.0\%) had $70 \%-99 \%$ stenosis and $14(2.1 \%)$ had total occlusion. The Society for Vascular Surgery and the ' 14 Society' guidelines advise that screening for ACAS should be considered in selected patients with multiple risk factors, such as a history of PAD. ${ }^{15} 16$ However, because some randomised controlled trials may overestimate the benefits of screening for carotid stenosis and DUS alone 
Table 4 Logistic regression analysis of risk factors for carotid artery stenosis in patients with PAD

\section{Degree of stenosis}

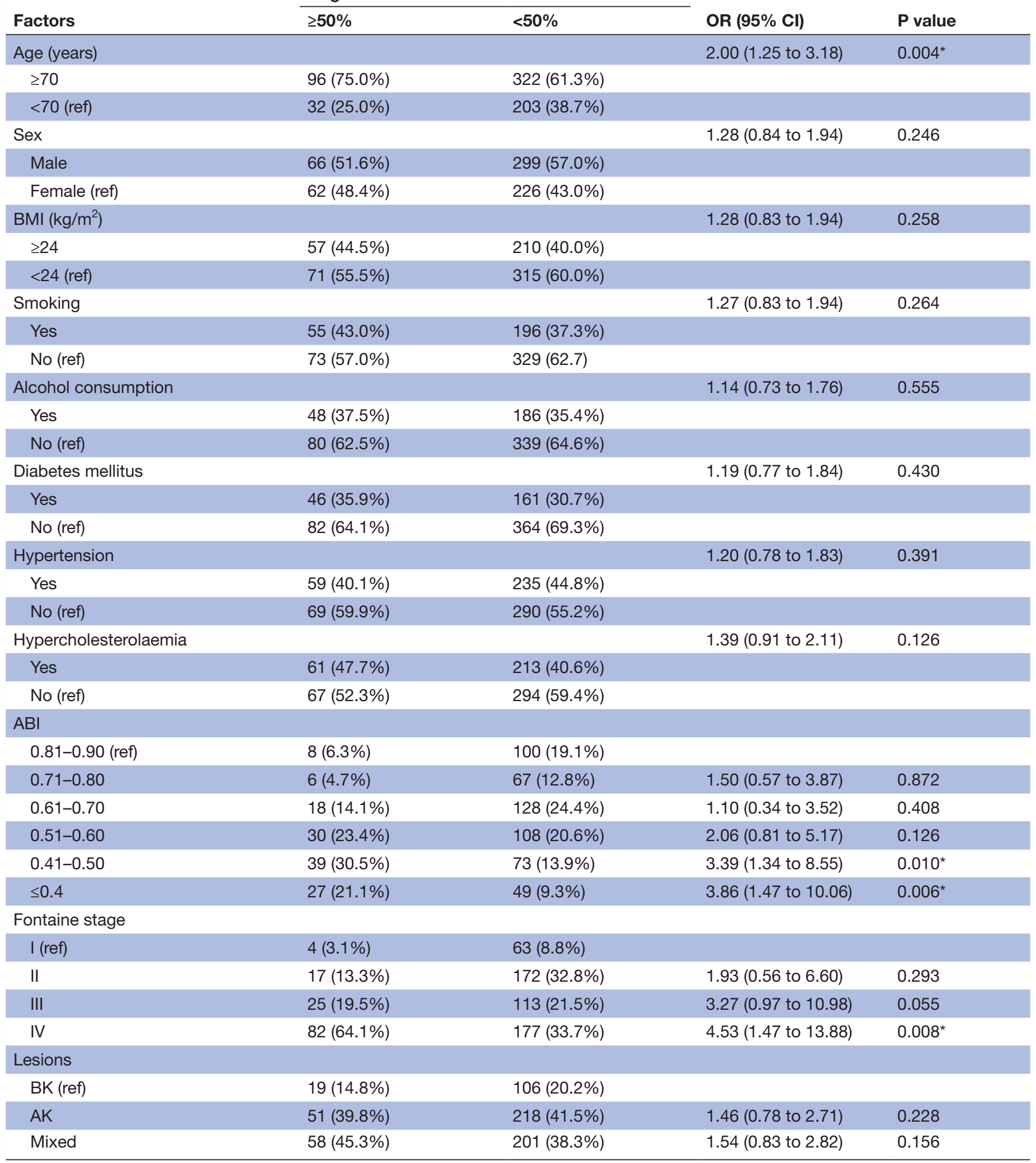

${ }^{*} \mathrm{P}<0.05$.

$\mathrm{ABI}$, ankle brachial index; $\mathrm{AK}$, above the knee; BK, below the knee; ;BMI, body mass index; PAD, peripheral arterial disease.

or even combined with MRA might lead to a large number of patients with false-positive results being diagnosed with significant ACAS, the US Preventive Services Task
Force recommends against screening for ACAS in any population group. ${ }^{417}$ The prevalence of ACAS is significantly higher among patients with PAD than the general 
Table 5 Previous studies screening patients with PAD for asymptomatic carotid artery disease

\begin{tabular}{|c|c|c|c|c|c|c|}
\hline \multirow[b]{2}{*}{ Author } & \multirow[b]{2}{*}{ Year } & \multirow[b]{2}{*}{ Country } & \multirow[b]{2}{*}{ Patients (n) } & \multicolumn{3}{|c|}{ Degree of stenosis } \\
\hline & & & & $50 \%-69 \%$ & $70 \%-99 \%$ & Occlusion \\
\hline Pan et $a l^{20}$ & 2019 & China & 200 & $29.5 \%$ & $22 \%$ & $1.5 \%$ \\
\hline Bez and Navarro ${ }^{38}$ & 2014 & Brazil & 100 & $40 \%$ & $17 \%$ & $2 \%$ \\
\hline Marsico et $a l^{39}$ & 2013 & Italy & 86 & None & $17 \%$ & None \\
\hline Yun et $a l^{22}$ & 2010 & South Korea & 340 & $6.8 \%-7.4 \%$ & $2.6 \%-5.6 \%$ & $2.4 \%-4.7 \%$ \\
\hline
\end{tabular}

None: not reported in the study.

$P A D$, peripheral arterial disease.

population, most likely because patients with PAD have multiple risk factors for systemic atherosclerosis, and thus screening for ACAS is necessary in select patients with PAD. Our results showed that the prevalence of significant ACAS in the PAD population in Southern China was lower than that in other countries and in Northern China reported in previous studies using the SRUCC criteria to diagnose ICA stenosis (table 3). This discrepancy may be explained by the fact that patients with a history of ischaemic stroke were excluded from our study, in addition to differences in sample size and the demographic characteristics of the study population. This finding is consistent with Greco's predictive model based on 2885 257 patients, which suggested that African-American, Asian and Hispanic participants had a low prevalence of ACAS. $^{18}$

According to a study by Poorthuis and colleagues, the best predictive model for screening ACAS should include age, sex, smoking, hypertension, hypercholesterolaemia, diabetes mellitus, vascular and cerebrovascular diseases, measured blood pressure and blood lipids. ${ }^{19}$ In our logistic regression model, we demonstrated that age older than 70 years, ABI less than 0.5 and Fontaine stage IV were independent risk factors for ACAS $>50 \%$ in patients with PAD. However, other atherosclerotic risk factors such as smoking, hypertension, diabetes mellitus and hypercholesterolaemia were not associated with the presence of significant ACAS in our study, possibly because these factors are highly prevalent in both patients with $\mathrm{PAD}$ and in patients with CAS, indicating that these variables are potential markers of systemic atherosclerosis. In our study, $75 \%$ of all detected stenoses were found in patients aged 70 years and older. Recently, Pan et al found that advanced age ( $\geq 70$ years) and hypercholesteraemia were potential risk factors for significant CAS in Northern Chinese patients with PAD. ${ }^{20}$ Jung et al and Yun et al found that age $>65$ years was significantly associated with $\geq 70 \%$ stenosis. ${ }^{21} 22$ In another study, the prevalences of moderate carotid stenosis and severe stenosis were $7.0 \%$ and $2.0 \%$, respectively, in patients older than 60 years in Northern China. ${ }^{23}$ These results suggest that the differences in the incidence of ACAS in patients with PAD are related to the age of the study population, as the risk of carotid stenosis increases with age in patients with PAD. These potential risk factors may be beneficial for screening for significant ACAS in patients older than 70 years.

At present, ACAS screening is not limited to concerns about stroke but focuses more on appropriate control of risk factors after screening to reduce the occurrence of cardiovascular disease. A decrease in ABI can predict an increased risk of cardiocerebrovascular disease. Previous studies have suggested that the risks of stroke and transient ischaemic attack are significantly increased in patients with PAD. ${ }^{24}$ However, the association between PAD severity quantified by ABI and CAS is not clear. A prior study involving 5224 Chinese people reported that the proportion of patients with $\mathrm{ABI} \leq 0.9$ was higher in the CAS population than in the non-CAS population, suggesting that a low $\mathrm{ABI}$ is a significant risk factor for ACAS in male and older adults. ${ }^{25}$ This study is consistent with a cross-sectional study of 933 participants reporting that $\mathrm{ABI}$ is a useful and non-invasive tool for the prediction of subclinical carotid and intracranial atherosclerosis in a Caucasian population. ${ }^{26}$ Furthermore, in the Japanese population of the Reduction of Atherothrombosis for Continued Health Registry, ABI less than 0.9 was a significant predisposing factor for stroke and ACAS $\geq 70 \%{ }^{27}$ The current study found that as ABI decreased, the proportion of patients with significant ACAS significantly increased. Patients with significant ACAS accounted for $51.6 \%$ of those with severe lower limb ischaemia and $\mathrm{ABI} \leq 0.5$. Logistic regression analysis showed that the risk of ACAS was significantly higher in patients with $\mathrm{ABI} \leq 0.5$ than in mildly ischaemic patients with $\mathrm{PAD}$ (ABI: 0.81-0.90). The current results confirm prior findings indicating that low $\mathrm{ABI}$ is an accurate indicator of asymptomatic cervicocerebral atherosclerosis and further identify a specific population of patients with PAD requiring intervention to prevent cardiocerebrovascular disease. With PAD aggravation, such as the occurrence of stage III and IV clinical manifestations, including resting pain and limb ulcers, the incidence of ACAS significantly increased. Among patients with stage IV PAD, 82 had significant CAS $(82 / 128,64.06 \%)$, a greater number than for the other stages. Previous studies have found that the incidence of symptomatic cerebral infarction 
was significantly increased in patients with PAD classified as Fontaine stages III and IV and that their cerebral infarction areas were larger than those of patients without PAD. ${ }^{28}$ However, the reason why symptomatic ischaemic stroke was frequently observed in patients with severe PAD is not clear. Two previous studies reported that carotid bruit, resting pain, age $>65$ years and $\mathrm{ABI}<0.7$ were associated with $>50 \%$ ACAS. ${ }^{29} 30$ Our study showed that the risk of patients with Fontaine stage IV PAD developing significant ACAS was higher than that of patients classified as stage I, which may explain the increased incidence of symptomatic cerebral infarction in patients with severe PAD with resting pain or extremity ulcers. Although the proportion of patients with above-knee and mixed lesions who had significant ACAS was significantly higher than that of patients with below-knee lesions alone $(39.84 \%$, $45.31 \%$ vs $14.84 \%$ ), logistic regression analysis revealed that the lesion location had no effect on ACAS, consistent with a previous finding that the incidence of severe ACAS $(>70 \%)$ among patients with multilevel lesions of lower extremity arterial atherosclerosis lesions was significantly higher than that among patients with iliac and infrainguinal lesions, but lesion location was not a significant risk factor for severe CAS in the multivariable analysis. ${ }^{21}$

Carotid revascularisation, including carotid endarterectomy (CEA) and carotid artery stenting, has long been the primary method of preventing stroke in screened patients with ACAS. According to the Asymptomatic Carotid Surgery Trial-1, however, only $4.6 \%$ strokes were prevented at 5 years after CEA, and 95\% of all CEA procedures were ultimately unnecessary. ${ }^{31}$ Therefore, the American Heart Association has repeatedly advised that only 'highly selected' asymptomatic patients should undergo CEA. ${ }^{32} 33$ Evidence suggests that the annual risk of stroke in patients with ACAS could be reduced by medical therapy alone. It is inevitable that a smaller subgroup with clinical and/or imaging features of 'higher risk for stroke' on medical therapy will benefit from carotid revascularisation. In future studies, a risk prediction model will be developed to identify high-risk patients with ACAS early, and the benefits and risks of medical therapy and carotid revascularisation will be evaluated to determine which treatment is more suitable for the high-risk patients who had a stroke in $\mathrm{PAD}$ population.

The present study had several limitations. First, patients with PAD with an ABI greater than 1.4 due to severe arterial calcification were excluded; therefore, the prevalence and risk of ACAS in these patients cannot be analysed. Second, our study focused on the degree of ACAS but not on plaque characteristics. Plaques with a large lipidrich necrotic core, intraplaque haemorrhage or luminal surface disruption, which are defined as high-risk plaques and are significantly associated with cerebrovascular events, ${ }^{34-36}$ are detected in symptomatic or asymptomatic carotid arteries with 30\%-99\% stenosis. ${ }^{37}$ Third, this study was a single-centre retrospective analysis, and the generalisability of the findings is limited because the study participants consisted of only Southern Chinese patients.
In conclusion, patients with significant ACAS (stenosis $\geq 50 \%$ ) accounted for approximately $19.6 \%$ of the PAD population. Significant ACAS was more common in symptomatic patients with PAD older than 70 years, particularly patients with $\mathrm{ABI}<0.5$ and classified as Fontaine stage IV. Identifying high-risk factors for ACAS in patients with PAD may substantially reduce the number of low-risk patients with PAD requiring ACAS screening. Selective screening of these high-risk individuals in the PAD population might be worthwhile.

Acknowledgements The authors thank Michiel H F Poorthuis for constructive advice on manuscript writing. The authors are also grateful to Zibing Deng and Rui Zhang for advice on statistical analysis.

Contributors LZ was responsible for the study design and participated in data collection, data analysis and manuscript drafting and submission. YH participated in data collection, data analysis, manuscript drafting and literature research. WZ and JW participated in data analysis, data interpretation, manuscript preparation and literature research. YZ and JC participated in the study design and were responsible for data interpretation and manuscript revision. All authors have approved the final version of the manuscript.

Funding This work was supported by the Chongqing Municipal Health Commission (grant number: 2015XMSB00784).

Competing interests None declared.

Patient and public involvement Patients and/or the public were not involved in the design, or conduct, or reporting, or dissemination plans of this research.

Patient consent for publication Not required.

Ethics approval This study was approved by the Ethics Committee of the First Affiliated Hospital of Chongqing Medical University (approval ID: 20172301). All participants provided written informed consent before taking part.

Provenance and peer review Not commissioned; externally peer reviewed.

Data availability statement All data relevant to the study are included in the article or uploaded as supplementary information. The data used to support the findings of this study are available from the corresponding author upon request.

Open access This is an open access article distributed in accordance with the Creative Commons Attribution Non Commercial (CC BY-NC 4.0) license, which permits others to distribute, remix, adapt, build upon this work non-commercially, and license their derivative works on different terms, provided the original work is properly cited, appropriate credit is given, any changes made indicated, and the use is non-commercial. See: http://creativecommons.org/licenses/by-nc/4.0/.

ORCID iD

Jun Cheng http://orcid.org/0000-0001-5076-4349

\section{REFERENCES}

1 Avan A, Digaleh H, Di Napoli M, et al. Socioeconomic status and stroke incidence, prevalence, mortality, and worldwide burden: an ecological analysis from the global burden of disease study 2017 . BMC Med 2019;17:191.

2 Feigin VL, Norrving B, Mensah GA. Global burden of stroke. Circ Res 2017;120:439-48.

3 Luengo-Fernandez R, Paul NLM, Gray AM, et al. Population-Based study of disability and institutionalization after transient ischemic attack and stroke: 10-year results of the Oxford vascular study. Stroke 2013;44:2854-61.

4 Jonas DE, Feltner C, Amick HR, et al. Screening for asymptomatic carotid artery stenosis: a systematic review and meta-analysis for the U.S. preventive services Task force. Ann Intern Med 2014;161:336-46.

5 Abbott AL, Bladin CF, Levi CR, et al. What should we do with asymptomatic carotid stenosis? Int J Stroke 2007;2:27-39.

6 Naylor AR. Why is the management of asymptomatic carotid disease so controversial? Surgeon 2015;13:34-43.

7 Giannopoulos A, Kakkos S, Abbott A, et al. Long-Term mortality in patients with asymptomatic carotid stenosis: implications for statin therapy. Eur J Vasc Endovasc Surg 2015;50:573-82. 
8 de Weerd M, Greving JP, Hedblad B, et al. Prediction of asymptomatic carotid artery stenosis in the general population: identification of high-risk groups. Stroke 2014;45:2366-71.

9 Naylor AR, Ricco J-B, de Borst GJ, et al. Editor's Choice Management of Atherosclerotic Carotid and Vertebral Artery Disease: 2017 Clinical Practice Guidelines of the European Society for Vascular Surgery (ESVS). Eur J Vasc Endovasc Surg 2018;55:3-81.

10 Gerhard-Herman MD, Gornik HL, Barrett C, et al. 2016 AHA/ACC guideline on the management of patients with lower extremity peripheral artery disease: a report of the American College of Cardiology/American heart association Task force on clinical practice guidelines. Circulation 2017;135:e726-79.

11 Grant EG, Benson CB, Moneta GL, et al. Carotid artery stenosis: grayscale and Doppler ultrasound diagnosis--Society of Radiologists in Ultrasound consensus conference. Ultrasound Q 2003;19:190-8.

12 Chen C, Lu FC, Department of Disease Control Ministry of Health, PR China. The guidelines for prevention and control of overweight and obesity in Chinese adults. Biomed Environ Sci 2004;17:1-36.

13 Bhat VM, Cole JW, Sorkin JD, et al. Dose-Response relationship between cigarette smoking and risk of ischemic stroke in young women. Stroke 2008;39:2439-43.

$14 \mathrm{Li}$ Q, Babor TF, Hao W, et al. The Chinese translations of alcohol use disorders identification test (audit) in China: a systematic review. Alcohol Alcohol 2011;46:416-23.

15 Ricotta JJ, Aburahma A, Ascher E, et al. Updated Society for vascular surgery guidelines for management of extracranial carotid disease. J Vasc Surg 2011;54:e1-31.

16 Brott TG, Halperin JL, Abbara S, et al. 2011 ASA/ACCF/AHA/AANN/ AANS/ACR/ASNR/CNS/SAIP/SCAI/SIR/SNIS/SVM/SVS guideline on the management of patients with extracranial carotid and vertebral artery disease: Executive summary: a report of the American College of cardiology Foundation/American heart association Task force on practice guidelines, and the American stroke association, American association of neuroscience nurses, American association of neurological Surgeons, American College of radiology, American Society of Neuroradiology, Congress of neurological Surgeons, society of atherosclerosis imaging and prevention, Society for cardiovascular angiography and interventions, society of interventional radiology, society of Neurolnterventional surgery, Society for vascular medicine, and Society for vascular surgery. J Am Coll Cardiol 2011:57:1002-44

17 , Krist AH, Davidson KW, et al, US Preventive Services Task Force. Screening for asymptomatic carotid artery stenosis: US preventive services Task force recommendation statement. JAMA 2021;325:476-81.

18 Greco G, Egorova NN, Moskowitz AJ, et al. A model for predicting the risk of carotid artery disease. Ann Surg 2013;257:1168-73.

19 Poorthuis MHF, Halliday A, Massa MS, et al. Validation of risk prediction models to detect asymptomatic carotid stenosis. J Am Heart Assoc 2020;9:e014766.

20 Pan Z, Wang R, Li L, et al. Correlation between significant asymptomatic carotid artery stenosis and severity of peripheral arterial occlusive disease in the lower limb: a retrospective study on 200 patients. BMC Neurol 2019;19:259.

21 Jung HJ, Lee SS, Kim HY, et al. Association between carotid artery stenosis and peripheral artery disease: evaluation by screening carotid ultrasonography (cross-sectional study). Medicine 2019;98:e14163.

22 Yun W-S, Rho Y-N, Park U-J, et al. Prevalence of asymptomatic critical carotid artery stenosis in Korean patients with chronic atherosclerotic lower extremity ischemia: is a screening carotid duplex ultrasonography worthwhile? J Korean Med Sci 2010;25:1167-70.

23 Yan Z, Liang Y, Shi J, et al. Carotid stenosis and cognitive impairment amongst older Chinese adults living in a rural area: a populationbased study. Eur J Neurol 2016;23:201-4.

24 Kolls BJ, Sapp S, Rockhold FW, et al. Stroke in patients with peripheral artery disease. Stroke 2019;50:1356-63.

25 Qiu J, Zhou Y, Yang X, et al. The association between Ankle-brachial index and asymptomatic cranial-carotid stenosis: a populationbased, cross-sectional study of 5440 Han Chinese. Eur J Neurol 2016;23:757-62.

26 Jiménez M, Dorado L, Hernández-Pérez M, et al. Ankle-Brachial index in screening for asymptomatic carotid and intracranial atherosclerosis. Atherosclerosis 2014;233:72-5.

27 Uchiyama S, Goto S, Matsumoto M, et al. Cardiovascular event rates in patients with cerebrovascular disease and atherothrombosis at other vascular locations: results from 1-year outcomes in the Japanese reach registry. J Neurol Sci 2009;287:45-51.

28 Aizawa H, Azuma N, Katayama T, et al. Cerebrovascular disease and intracranial artery stenosis in patients with symptomatic peripheral artery disease. J Stroke Cerebrovasc Dis 2012;21:825-31.

29 Jahromi AS, Clase CM, Maggisano R, et al. Progression of internal carotid artery stenosis in patients with peripheral arterial occlusive disease. J Vasc Surg 2009;50:292-8.

30 Cinà CS, Safar HA, Maggisano R, et al. Prevalence and progression of internal carotid artery stenosis in patients with peripheral arterial occlusive disease. J Vasc Surg 2002;36:75-82.

31 Halliday A, Harrison M, Hayter E, et al. 10-Year stroke prevention after successful carotid endarterectomy for asymptomatic stenosis (ACST-1): a multicentre randomised trial. Lancet 2010;376:1074-84.

32 Meschia JF, Bushnell C, Boden-Albala B, et al. Guidelines for the primary prevention of stroke: a statement for healthcare professionals from the American heart Association/American stroke association. Stroke 2014;45:3754-832.

33 Goldstein LB, Bushnell CD, Adams RJ, et al. Guidelines for the primary prevention of stroke: a guideline for healthcare professionals from the American heart Association/American stroke association. Stroke 2011;42:517-84.

34 Singh N, Moody AR, Gladstone DJ, et al. Moderate carotid artery stenosis: Mr imaging-depicted intraplaque hemorrhage predicts risk of cerebrovascular ischemic events in asymptomatic men. Radiology 2009:252:502-8.

35 Sadat U, Weerakkody RA, Bowden DJ, et al. Utility of high resolution MR imaging to assess carotid plaque morphology: a comparison of acute symptomatic, recently symptomatic and asymptomatic patients with carotid artery disease. Atherosclerosis 2009;207:434-9.

36 Takaya N, Yuan C, Chu B, et al. Association between carotid plaque characteristics and subsequent ischemic cerebrovascular events: a prospective assessment with MRI--initial results. Stroke 2006;37:818-23.

37 Zhao X, Hippe DS, Li R, et al. Prevalence and characteristics of carotid artery High-Risk atherosclerotic plaques in Chinese patients with cerebrovascular symptoms: a Chinese atherosclerosis risk evaluation II study. J Am Heart Assoc 2017;6.

38 Bez LG, Navarro TP. Study of carotid disease in patients with peripheral artery disease. Rev Col Bras Cir 2014;41:311-8.

39 Marsico F, Giugliano G, Ruggiero D, et al. Prevalence and severity of asymptomatic coronary and carotid artery disease in patients with abdominal aortic aneurysm. Angiology 2015;66:360-4.

40 Bavil AS, Ghabili K, Daneshmand SE, et al. Prevalence of significant carotid artery stenosis in Iranian patients with peripheral arterial disease. Vasc Health Risk Manag 2011;7:629-32. 